Research Article

\title{
Construction of Control Rights Allocation Index of Listed Companies Based on Neural Network and Machine Learning
}

\author{
Tao Zhang ${ }^{1,2}$ and Yuxiang Peng $\mathbb{D}^{1}$ \\ ${ }^{1}$ School of Economics and Management, Xi'an University of Technology, Xi'an 710048, Shaanxi, China \\ ${ }^{2}$ Business School, Gansu University of Political Science and Law, Lanzhou 730070, Gansu, China \\ Correspondence should be addressed to Yuxiang Peng; 1180511013@stu.xaut.edu.cn
}

Received 17 December 2020; Revised 20 February 2021; Accepted 9 March 2021; Published 22 March 2021

Academic Editor: Ming Bao Cheng

Copyright (c) 2021 Tao Zhang and Yuxiang Peng. This is an open access article distributed under the Creative Commons Attribution License, which permits unrestricted use, distribution, and reproduction in any medium, provided the original work is properly cited.

\begin{abstract}
Control power is a core issue that every listed company pays great attention to. The company's shareholding structure directly affects the allocation of control rights. Therefore, the shareholding structure of listed companies is analyzed, and various factors related to the allocation of company control rights are discussed. It is very important to build indicators of control allocation of listed companies and improve the governance model of listed companies. Based on this, this article proposes to use neural networks and machine learning techniques to build related models and solve related problems. This article takes the control allocation index of listed companies on the SSE and SZSE platforms under good securities' market conditions as the research object and takes the stock holding allocation of listed companies as a reference for the control allocation index. Combine sliding removal technology and approximate entropy with sample entropy, select the sliding window and sliding step size as 21 data, keep the sliding window unchanged, and calculate the approximate entropy and sample entropy of the sequence after removing 21 data for each sliding value to analyze the correlation between the rate of return, complexity, and effectiveness. The results of the study show that the mean and median of the majority shareholder's equity pledge behavior are 0.249 and 0 , respectively, and the mean and median of the majority shareholder's equity pledge ratio are 0.147 and 0 , respectively, indicating that $24.9 \%$ of the companies in the sample have major shareholder equity. Pledge is limited by sample data, and the proportion of major shareholders' equity pledge is moderate, which means that there is a certain gap in the quality of internal control between companies.
\end{abstract}

\section{Introduction}

Since the reform and opening up, our country's market economy has developed rapidly, but there is still a big gap between the stock market and developed countries, which is mainly reflected in the company's shareholding structure and company management and governance. This reflects that there is a big problem with the control allocation index of listed companies. Some personnel hold large-scale management rights in a small number of shares and are subject to improper management or sanctions during this period, reducing related profits. Faced with these problems, this paper studies the research results related to financial management and, on this basis, conducts the research on the corporate control allocation index.
Most researchers take investment as their main research direction. For example, Zhou Min's research found that the introduction of nonexecutive directors is conducive to improving the independence of the board of directors, curbing managerial conservatism, supervising the company's excessive investment behavior, and promoting innovative output $[1,2]$. Ying believes that, in the form of centralized power, nonexecutive directors, as the spokesperson for the interests of major shareholders, have stronger supervisory motivation and ability and have a significant "supervisory effect" on enterprise innovation output [3]. Pan pointed out that nonexecutive directors often work in parent companies or affiliated companies, and they know the company better than part-time independent directors, and they have rich industry experience and a good relationship 
network. They cannot only provide professional consulting and advice to companies but also provide companies with more external resources to promote the transformation of innovation output results [4]. Xiaofang and Zhao believe that, in the form of relatively centralized power, the conflict of interest between the controlling shareholder and other major shareholders is more serious, and the "same bed and different dreams" in the process of promoting the transformation of innovation output are not conducive to the innovation output of enterprises [5]. Based on the panel data of 153 companies listed on the Board of Directors of the Growth Enterprise Market (GEM) in 2020, Zhang and Erasmus's research analyzes the status quo of the ownership structure and company performance and explores the mechanism of the company's ownership structure on the company [6].

From the perspective of enterprise life cycle heterogeneity, Lusk et al. believe that the feedback between executive incentives and corporate performance presents different effects at different stages [7]. In terms of corporate innovation investment, Gupta et al.'s effective innovation activities can help companies gain competitive advantages and benefits, especially for high-tech companies that rely on emerging technologies to make their fortunes, and stable innovation investment is the source of life to ensure their development. For nonhigh-tech enterprises, innovation investment is not the decisive factor for their development $[8,9]$. Dalla et al. proposed that the level of executive incentives can affect the decision-making of corporate innovation activities to a certain extent. The increase in executive compensation makes the executives more enthusiastic about innovation activities and the greater the intensity of corporate innovation investment [10]. Ding et al. believe that the more concentrated the equity, the more effective it is to control the behavior of executives and ensure that executives invest more funds in innovative activities. At the same time, according to the supervision theory, the concentration of equity can increase the restraint on executives' decisionmaking and avoid the pursuit of executives. Private interests harm the efficiency of enterprises and ensure that executives make reasonable decisions and innovative activities to enhance corporate performance [11]. Shouqing et al.'s research shows that when equity concentration meets certain conditions, the relationship between salary incentives and corporate performance can be revealed, but no adjustment of equity concentration has been found [12].

This article first summarizes the current status of management control allocation schemes at home and abroad, compares the characteristics of the implementation of the management control allocation index at home and abroad, and draws a conclusion. Secondly, it uses control allocation theory and enterprise manager theory. Classical theory provides a more comprehensive and detailed analysis of the management control assignment index and believes that the implementation of the management control assignment plan is feasible. Third, the establishment of an optimal allocation model of equity. The concept of "agent state" is proposed, and the ownership structure and agency cost are connected through the agency state. The ownership structure determines the agency state, and the agency state determines the agency cost. Based on this, an optimal allocation model of equity from the perspective of controlling agency costs is established. From the perspective of improving company performance, a general model of optimal allocation of equity is established, and combined with the control of agency costs; a decision analysis table for optimal allocation of equity is formulated. Finally, the model established in this paper is tested with the case of the domestic management control allocation plan, and the results show that the model has a certain degree of scientificity and guidance.

\section{Allocation Index Model under the Neural Network and Machine Learning Method}

2.1. Control-Type Division Method Based on the Control Right Realization Coefficient. Control power is the basis of property rights for deepening reform, and deepening reform is a rational choice to consolidate control power [13]. The reform is not to give up control, but to ensure control in the process of reducing state-owned shares and giving priority to ensuring the dominant position of the state-owned economy in major issues [14]. Based on Berle's classification of control rights and the estimation of the optimal control rights threshold, the control types after the mixed ownership reform are divided into three interval types:

(1) Weak type: the controlling shareholder's direct shareholding ratio is less than $20 \%$, meaning weak control; state-owned enterprises have a tendency to privatize, and the nonstate-owned capital has a certain degree of control over the decision-making of state-owned enterprises, which can easily lead to malicious embezzlement of state-owned assets [15].

(2) Semistrong type: the controlling shareholder's shareholding is concentrated in the $20 \%-50 \%$ range, and the controlling shareholder has weaker control [16]. The controlling shareholder of a semistrong company has strong control, but the controlling shareholder of a semistrong company has volatility [17]. Still, large state-owned enterprises in the region may lose control due to the ambiguity of property rights transactions [18].

(3) Strong: the controlling shareholder holds more than $50 \%$ of the shares, the state-owned enterprises in the region are highly concentrated, and the participation of the nonstate-owned capital is insufficient [19]. According to the principle of the division of control types by controlling shareholders, it is believed that the mixed reform is centered on the main line of "guaranteeing control rights," continuously optimizing the structure of equity checks and balances, and ultimately achieving the goal of mutual promotion of the private capital [20].

2.2. Control Power-Realization Coefficient Validity Function. According to the control realization coefficient, the effectiveness of controlling shareholders' control over the 
enterprise is defined as the validity of the control realization coefficient [21]. The control right realization coefficient $(Z)$ is mainly determined by the controlling shareholder's shareholding ratio (A1) and the control right threshold $(\mathrm{P} * *)$ [22]. This coefficient can effectively measure the validity of the control right allocation after the mixed ownership reform [23]. At the same time, using the more commonly used contingency chart in qualitative analysis, the three intervals of the threshold of control rights are combined with the three types of controlling shareholder's shareholding ratio, and the matching and combination of the control rights realization coefficient types are analyzed to obtain the control rights [24]. According to the actual control types of the controlling shareholders of state-owned enterprises after the mixed ownership reform, they are reclassified into the following three types:

(1) Invalid control type: C2, E2, F, G2, H, and I areas. This type of state-owned enterprise has control power realization coefficient $Z<1$, the controlling shareholder cannot effectively control the major issues of the enterprise, and the control right will increase the risk of state-owned assets and private ownership [25]. Among them, the $\mathrm{C} 2$ area belongs to the strong type of controlling shareholder control [26]. At this time, the company's equity is highly concentrated, and the participation of the private capital is also relatively large [27]. There is no benign balance between the state-owned capital and nonstate-owned capital, and state-owned enterprises fail to protect their control rights; $\mathrm{E} 2$ and $\mathrm{F}$ areas belong to the semistrong type of control types. At this time, the company's equity is relatively concentrated, but the nonstate capital has too much power to speak, but the control chain fails to play its actual role; In $\mathrm{G} 2, \mathrm{H}$, and I areas, the control type of the controlling shareholder is weak. Although the company's shareholding structure is relatively dispersed at this time, the nonstate-owned capital is still in the most advantageous position.

(2) Effective control type: In D, E1, and G1 areas, the controlling shareholder of this type of Chinese stateowned enterprise has a significant advantage in the operation of the enterprise. The control realization coefficient is Z1, and the enterprise ownership structure is relatively reasonable, which can effectively prevent problems such as "one share dominance" and controlling shareholder abuse of control. Under such a well-balanced shareholding structure, state-owned enterprises cannot only expand the voice of the private capital and effectively release the vitality of state-owned enterprises but also guarantee control rights to prevent the loss of state-owned assets. Among them, the D and E1 areas belong to the semistrong control type. The shareholding structure of enterprises in this area is relatively concentrated, and the state-owned capital and nonstate-owned capital form a good check and balance effect, creating a more fair competition environment for enterprises. The G1 area is a weak type of control. The company's shareholding structure in this area is relatively decentralized. Effective reduction of state-owned stocks will be further realized without affecting control, the process of mixed ownership reform will be accelerated, and state-owned enterprises will be satisfied with the requirements for equity diversification.

(3) Excess control type: In A, B, and C1 areas, although such state-owned enterprises have the control rights realization coefficient $Z$, the control rights of controlling shareholders obviously overflow, which is manifested in the obvious phenomenon of "one share dominance" of the state-owned capital; the state-owned capital has a high degree of autonomy and strong government intervention ability. The shareholding ratio of the controlling shareholders of the companies in the $\mathrm{A}, \mathrm{B}$, and $\mathrm{C} 1$ regions is strong, and the process of reforming the integration and win-win situation of the state-owned capital and private capital has been greatly hindered.

2.3. Grey Absolute Proximity Correlation Model under Neural Network and Machine Learning. When carrying out multifactor evaluation, weights are usually used to reflect the importance of index factors, and common weighting methods are analyzed to make up for the shortcomings of single weighting methods. Therefore, the use of combined weighting methods for research in this paper is reliable and advanced.

2.3.1. Fuzzy Weight. Based on the influencing factor index system constructed above, the scoring results are weighted and averaged to obtain the fuzzy complementary matrix of each influencing factor $R=\left(r_{i j}\right)_{n \times n}$, and according to the formula,

$$
f_{i j}=\frac{r_{i}-r_{j}}{2(n-1)}+0.5 \text {. }
$$

Calculate the weights of primary and secondary indicators $w_{i}^{1}$ and $w_{i}^{3}$ :

$$
\begin{aligned}
& w_{i}^{k}=\frac{1}{n}-\frac{1}{2 \alpha}+\frac{\sum_{j=1}^{n} r_{i j}}{n \alpha}, \quad(i, k=1,2, \ldots, n), \\
& w_{i}^{2}=w_{i}^{2} \times\left(w_{i 1}^{2}, w_{i 2}^{2}, \ldots, w_{i j}^{2}\right)^{T} .
\end{aligned}
$$

Among them,

$$
\begin{aligned}
& r_{i}=\sum_{j=1}^{n} r_{i j}, \quad(i, j, \ldots, n), \\
& \alpha=\frac{(n-1)}{2} .
\end{aligned}
$$

2.3.2. Entropy Method to Determine Weights. Based on the data obtained from questionnaire surveys, the average value of the top five industry results is selected to construct an 
index evaluation matrix $P=\left(P_{i j}\right)_{n \times k} ;$ among them, $i=1,2, \ldots, n$ and $j=1,2, \ldots, k$, and carry out dimensionless processing for each index, and calculate the weight of the first and second index $h_{i}^{1}$ and $h_{i}^{2}$ according to the following formula:

$$
\begin{aligned}
& p_{i j}^{\prime \prime}=\frac{P_{i j}^{\prime}}{\sum_{i=1}^{n} P_{i j}^{\prime}} \quad(i=1,2, \ldots, n, j=1,2, \ldots, k), \\
& e_{j}=-\frac{1}{\ln k} \sum_{i=1}^{n} p_{i j}^{\prime \prime} \ln p_{i j}^{\prime \prime}, \quad(i=1,2, \ldots, n, j=1,2, \ldots, k), \\
& h_{i}=\frac{\left(1-e_{j}\right)}{\sum_{j=1}^{k}\left(1-e_{j}\right)}, \quad(j=1,2, \ldots, k) .
\end{aligned}
$$

Finally, combine the weight $w_{i}$ and $h_{i}$ according to the following formula to get the first and second index combination weight $t_{i}$ and the ranking of organizational innovation factors:

$$
\begin{aligned}
t_{i} & =\frac{w_{i} h_{i}}{\sum_{i=1}^{n} w_{i} h_{i}}, \quad(i=1,2, \ldots, n), \\
f(x) & =\frac{1}{N h} \sum_{i=1}^{N} k\left(\frac{X_{i}-x}{h}\right) .
\end{aligned}
$$

It can be seen from the above formula that the primary indicators that affect organizational innovation are mainly technology, knowledge, organizational structure, and strategic characteristics; secondary indicators are mainly organizational learning, knowledge flow, and information technology. At the same time, in order to explore the logical relationship of the main influencing factors, select the first $80 \%$ of the secondary indicators as the main influencing factors and further analyze the influence mechanism between the factors.

\subsubsection{Analysis of the Impact Mechanism of Organizational} Innovation. The Interpretive Structure Model (ISM) construction of ISM can be used to analyze complex systems and visually express the logical relationship between factors, thereby constructing ISM to explore the hierarchical relationship between factors. By issuing questionnaires to universities and experts in various industries, the value of element $C$ is 1 or 0 , indicating whether the element $C_{i}$ pair $C_{j}$ has a direct impact, and the threshold is set to $80 \%$ to determine the correlation between factors, and the adjacency matrix $\mathrm{C}$ is established based on the correlation; on this basis, using MATLAB programming to perform multiple Boolean operations makes

$$
\begin{aligned}
M= & (C+I)^{k}=(C+I)^{k-1} \neq(C+I)^{k-2} \neq \cdots \\
& \neq(C+I)(k \leq n-1), \\
h_{t}= & \tanh \left(w_{c} x_{t}+u_{c}\left(r_{t} \Theta h_{t-1}\right)+b_{c}\right), \\
h_{t}= & z_{t} \Theta h_{t-1}+\left(1-z_{t}\right) \Theta h_{t} .
\end{aligned}
$$

The reachable matrix $M$ is obtained, and the hierarchical division is carried out according to the reachable set $=$ common set, and finally, the explanatory structure model of the influence factors is obtained. From the analysis of the model's path of influence, the processes that influence organizational innovation originate from information technology, market environment, and economic policy, and by acting on organizational structure and strategy and cultural and leadership qualities, it manifests itself in the flow of knowledge, organizational learning, and collaborative openness. The total number of shares is $T=\sum_{i=1}^{N} S_{i}$, and the shareholding ratio of the $i$ th shareholder is $P_{i}=S_{i} / T$. The calculation formula of the control degree $\alpha$ of the Cubbin-Leech model under the resolution of major issues is

$$
\begin{aligned}
\alpha & =\operatorname{Pr}\left(M^{\prime}>0\right)=\Phi\left(\frac{P_{1} T}{\sigma_{y}}\right)=\Phi\left(\frac{P_{1} T}{\sqrt{\theta \sum_{i=2}^{N} S_{i}^{2}}}\right) \\
& =\Phi\left(\frac{P_{1} T}{\sqrt{\theta\left(H-P_{1}^{2}\right)}}\right) .
\end{aligned}
$$

For the calculation of the shareholding ratio of other shareholders, refer to the extreme concentration method, that is, assuming the number of other shareholders as 10,000 to divide the remaining shares equally, you can get

$$
\begin{aligned}
H & =H_{10}+10000 \times\left(\frac{1-A_{10}}{10000}\right)^{2}, \\
\sigma t & =\frac{\sqrt{(1 / n) \sum_{i=1}^{n}\left(F I_{i t}-F I_{i t}\right)^{2}}}{F I_{i t}}, \\
u_{(j \mid i)} & =w_{i j} A_{i} .
\end{aligned}
$$

Combining formula (10) can obtain the control degree $\alpha$ of the controlling shareholder of the listed company. Conversely, if you directly limit the controlling shareholder's degree of control over the company $\alpha$ ( $\alpha$ should be large enough, such as $\alpha=95 \%$ or $99 \%$ ), you can calculate the minimum shareholding ratio required to control the company's decision-making, that is, optimal control weight threshold $P^{* *}$, and the calculation formula is

$$
\begin{aligned}
P^{* *} & =Z_{\alpha} \sqrt{\theta \times \frac{H}{1+Z_{\alpha}^{2} \theta}} \\
\ln \left(\frac{F I_{i t}}{F I_{i t}-1}\right) & =\alpha+\beta \ln F I_{i t}-1+v_{i}+\mathfrak{\Im}_{t} .
\end{aligned}
$$

Among them, $Z_{\alpha}$ is a normal discrete variable with predefined control rights. Then, define the control right realization coefficient as

$$
\begin{gathered}
Z=\frac{A_{1}}{P_{99 \%}} \\
\ln \left(\frac{F I_{i t}}{F I_{i t}-1}\right)=\alpha+\beta \ln F I_{i t}-1+\phi X_{i t}-1+v_{i}+\tau_{t} .
\end{gathered}
$$




\section{Construction of the Allocation Rights' Control Index of Listed Companies}

3.1. Data Sources of Experimental Samples. The sample data selected in this article are the equity information of listed companies on the Shanghai Securities Platform (SSE) and Shenzhen Constituent Stocks Platform (SZSE) to reflect the allocation of control rights. The data span is from January 1, 2014 to December 31, 2020. Transaction information data between SSE uses big data to optimize business ecology, adjust organizational structure, and realize securities' trading. Its self-developed C2M-personalized customization platform and digital cloud service platform form a virtuous circle ecosystem to facilitate securities' transactions for listed companies. Therefore, in this article, we will take as an example the composition of control of listed companies on the SSE and SZSE platforms to illustrate the impact mechanism of the assignment of control in the age of big data. The data source is Google Data Analysis.

3.2. Research Index Selection and Research Steps. According to the implementation goals and steps of the adjustment of control rights allocation, the process of adjustment of control rights allocation can be divided into three time periods: the trial period (May 9, 2017 September 9, 2017), the comprehensive control rights allocation adjustment period (2017) (September 12, 2018 September 29, 2018), and the critical period for the adjustment of control right allocation (after October 9, 2018). Therefore, the selected data is divided into four time periods: preadjustment phase, pilot phase, full implementation phase, and critical phase.

In order to initially understand the effectiveness and complexity of the Chinese stock market before and after the adjustment of the control allocation, first of all, descriptive statistics are performed on the selected SSE and SZSE return rate series. The sample size of the two series is 854 . The sample size is 327 , and the sample size after the adjustment of the control configuration is 394 , as shown in Table 1.

The Kurtosis values of SSE and SZSE before and after the adjustment of control rights allocation are both greater than 3 , and the skewness value is greater than 0 , indicating the instability of stock market returns. At the same time, combining the J-B test value and the return value $h$ is equal to 1 ; it can be determined that the return rate sequence rejects the assumption of a normal distribution. This shows that the distribution of stock market returns cannot be reasonably explained by the efficient market hypothesis, and its volatility does not follow periodic or completely random walks, which can preliminarily reflect the impact of the adjustment of the allocation of control rights on the effectiveness of the stock market.

\section{Dynamic Analysis of the Effectiveness and Complexity of Control Rights Allocation Based on Neural Networks and Machine Learning}

4.1. Relationship between Effectiveness and Complexity. This part mainly studies the optimal allocation of the equity structure from both theoretical and empirical aspects. In theoretical research, the impact of different equity concentration and equity checks and balances on the company's supervision mechanism, the exercise of shareholder power, and the company's takeover of the market is discussed, which theoretically proves the necessity of the optimization of the equity structure and the existence of the optimal equity structure problem.

In order to explore the dynamic changes of the effectiveness and complexity of the stock market by the adjustment of control rights allocation, this paper analyzes the dynamic values of the approximate entropy and sample entropy of the SSE and SZSE annual return series from 2014 to 2020, as shown in Figure 1. It can be seen that the SSE and SZSE are on the rise, indicating that the complexity of the stock market is increasing. As a result, the stock market is getting closer to the random state, the randomness of the stock price gradually increases, the predictability of the stock price decreases, and the effectiveness of the stock market is also has been promoted. At the same time, the approximate entropy or sample entropy of different sequences has similar changes, and there are local differences between the approximate entropy and sample entropy of the same sequence.

As shown in Table 2, the change characteristics of the entropy value of the SSE and SZSE stock market sequences can be obtained. The mean and median of the pledge of major shareholders' equity are 0.249 and 0 , respectively, and the mean and median of the percentage of major shareholders' equity pledges are 0.147 and 0 , respectively, indicating that $24.9 \%$ of the companies in the sample have pledged major shareholders' equity, which is restricted. In relation to sample data, the majority shareholder's equity pledge ratio is moderate, which means that there is a certain gap in the quality of internal control between companies. In 2017, Pilot Notices, Guidance, and Control Measures were issued to adjust the distribution of control of listed companies, formal initiation and implementation of adjustment of the distribution of control, and "not tradeable with the same share" "same rights" for stocks that can be traded with stocks. The operating mechanism of the stock market gradually improves the effectiveness of the market, which is manifested in the fact that the fluctuation of stock prices is closer to the supply and demand of the market so that the 
TABLE 1: Sample size after adjustment of control configuration.

\begin{tabular}{|c|c|c|c|c|c|}
\hline Time & Stock index & Mean & Skewness & Kurtosis & $\mathrm{J}-\mathrm{B}$ value \\
\hline \multirow{2}{*}{ Early stage of share reform } & SSE & 1.19 & 1.24 & 0.58 & 0.97 \\
\hline & SZSE & 3.53 & 1.01 & 1.9 & 2.68 \\
\hline \multirow{2}{*}{ Late share reform } & SSE & 5.62 & 5.53 & 3.93 & 5.54 \\
\hline & SZSE & 4.62 & 2.41 & 3.41 & 2.2 \\
\hline \multirow{2}{*}{ Full time period } & SSE & 1.68 & 1.59 & 1.87 & 1.21 \\
\hline & SZSE & 4.68 & 3.61 & 2.28 & 3.07 \\
\hline
\end{tabular}

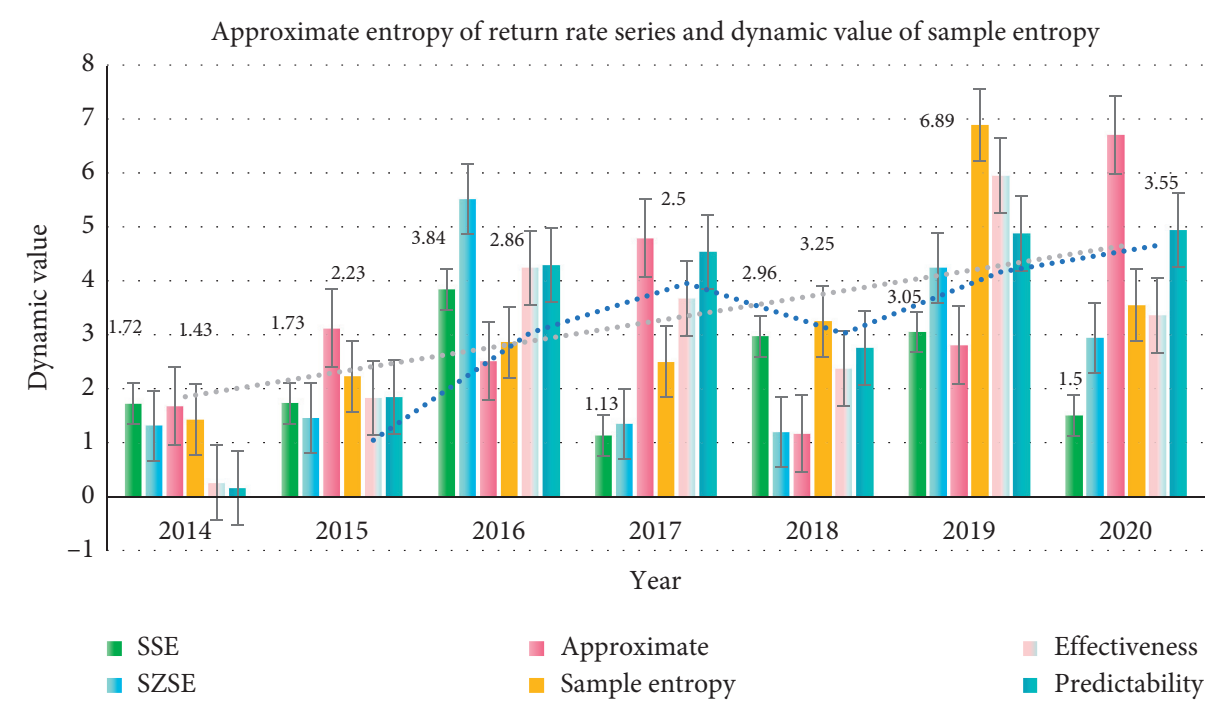

FIGURE 1: Approximate entropy of return rate series and dynamic value of sample entropy.

TABLE 2: The change characteristics of the entropy value of the SSE and SZSE stock market.

\begin{tabular}{lcccccc}
\hline Year & SSE & SZSE & Approximate & Sample entropy & Effectiveness & Predictability \\
\hline 2014 & 1.72 & 1.31 & 1.68 & 1.43 & 0.26 & 1.83 \\
2015 & 1.73 & 1.46 & 3.12 & 2.23 & 4.24 & 1.85 \\
2016 & 3.84 & 5.51 & 2.51 & 2.86 & 3.67 & 4.29 \\
2017 & 1.13 & 1.35 & 4.79 & 3.5 & 2.37 & 4.54 \\
2018 & 2.96 & 1.19 & 1.17 & 6.89 & 5.95 & 2.75 \\
2019 & 3.05 & 4.23 & 2.81 & 3.55 & 3.36 & 4.94 \\
2020 & 1.5 & 2.94 & 6.7 & & \\
\hline
\end{tabular}

formation of stock prices is getting closer and closer to randomness, and the entropy of the sequence sample reaches the local maximum in that year.

As shown in Figure 2, from 2014 to 2020, the sample entropy of the sequence showed a slight increase. This is mainly due to the fact that, in June 2014, the China Securities Regulatory Commission imposed a certain restriction on illegal manipulation of additional new shares, reducing artificial speculation or behaviors such as insider manipulation that interfered with the normal operation of the stock market and have increased the randomness of stock prices or yields, and the effectiveness of the stock market has also been slightly improved. After 2015, the China Securities Regulatory Commission continued to intensify its crackdown on illegal acts of manipulating the stock market, which provided support for capital market pricing to more closely reflect changes in the market supply and demand.
As shown in Table 3, the overall stability of the stock market from 2014 to 2020 reflects the increasing benefits brought about by the allocation of control rights of listed companies. It also verifies that, in 2016, government departments have successively issued the opening and stability of the stock market, protecting public investment and activating. There are several opinions and regulations on the vitality of the stock market and the improvement of the effectiveness of the stock market. The sample entropy of the series in that year has continued to increase, and the effectiveness of the stock market has improved to a certain extent.

As shown in Figure 3, in 2018 and 2019, the entropy of sequence samples showed a downward trend and reached a local minimum in 2019. This is mainly due to multiple capital violations and manipulations in 2018, with the majority of public investors and their strong "herd effect" 


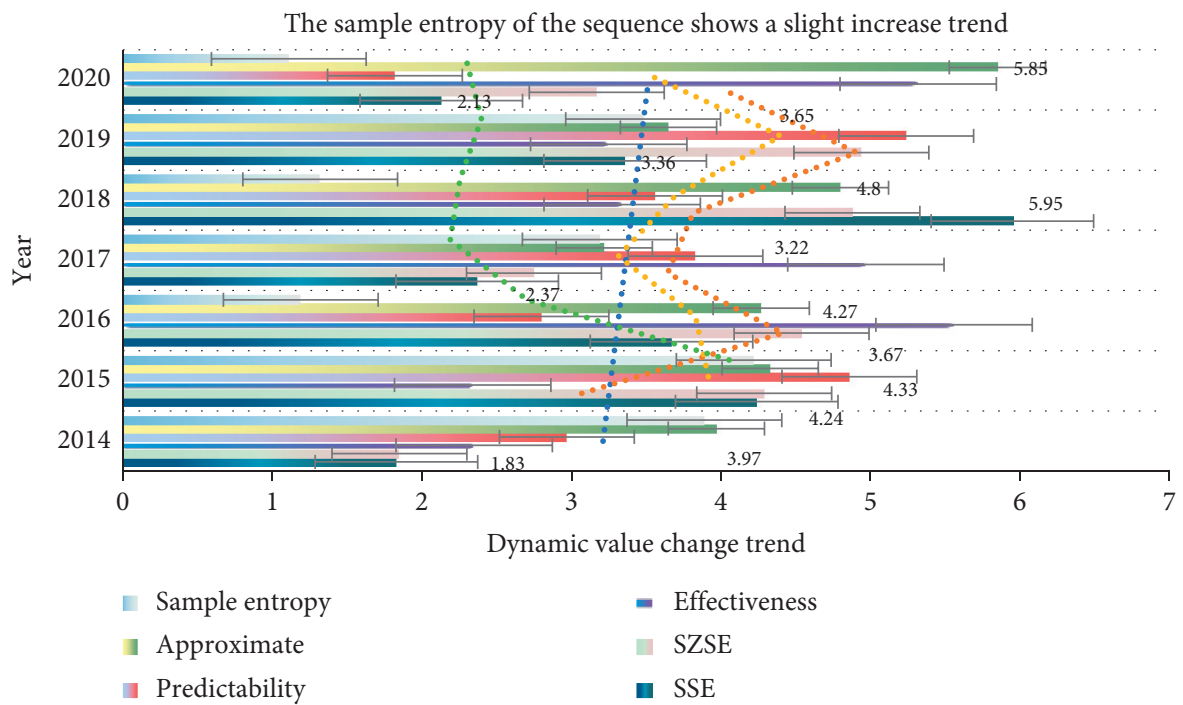

Figure 2: The sample entropy of the sequence shows a slight increase trend.

TABle 3: Sequence sample entropy reaches the local value.

\begin{tabular}{llccccc}
\hline Year & SSE & SZSE & Approximate & Sample entropy & Effectiveness & Predictability \\
\hline 2014 & 1.83 & 1.85 & 3.97 & 3.89 & 2.35 & 2.34 \\
2015 & 4.24 & 4.29 & 4.33 & 4.22 & 5.56 & 4.86 \\
2016 & 3.67 & 4.54 & 4.27 & 1.19 & 4.97 & 2.8 \\
2017 & 2.37 & 2.75 & 3.22 & 1.32 & 3.34 & 3.83 \\
2018 & 5.95 & 4.88 & 4.8 & 3.48 & 5.32 & 5.24 \\
2019 & 6.36 & 4.94 & 3.65 & 4.11 & 6.82 \\
2020 & 8.13 & 5.17 & 5.85 & & \\
\hline
\end{tabular}

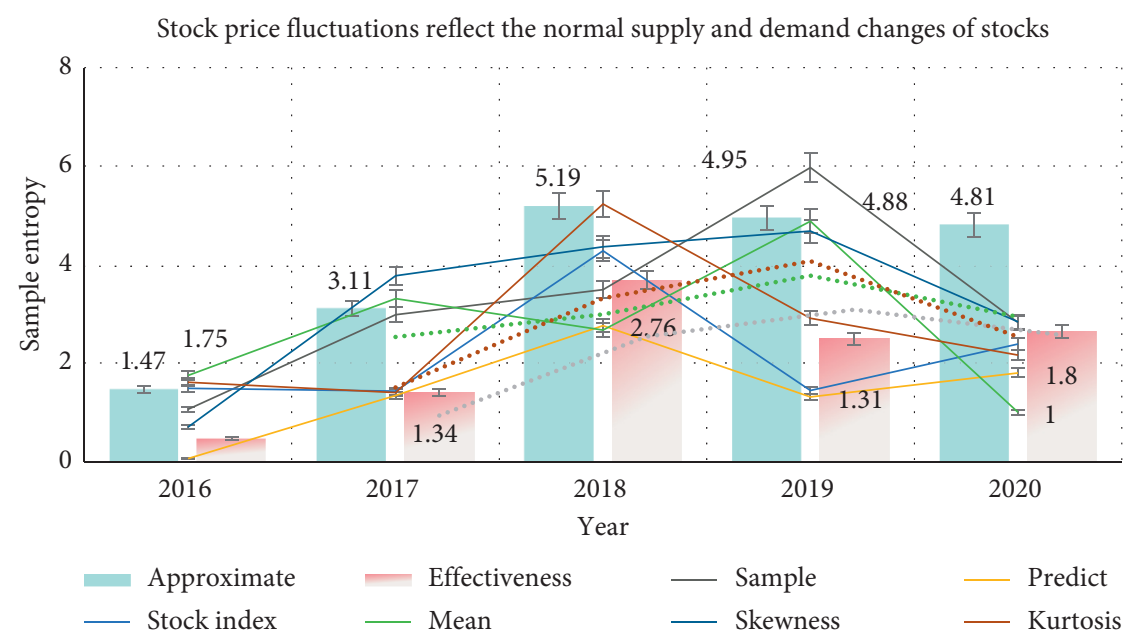

Figure 3: Stock price fluctuations reflect the normal supply and demand changes of stocks.

psychology, making stock price fluctuations unable to reflect the normal supply and demand changes of stocks. Although the China Securities Regulatory Commission issued a notice in May 2019 to further strengthen the education of investors and strengthen market supervision and management to regulate the normal operation of the capital market, as the opening up of China's stock market continues to increase, it is in contact with the international capital market increasingly closer and is more sensitive to the international market. As a result, the US subprime mortgage crisis and the US stock market crash that year spread rapidly to the Chinese stock market. In addition, the Chinese stock market is still in 
the development stage and has its own shortcomings. Under the interaction of policy and environmental factors, although the government has introduced favorable measures for the market, the further improvement of the effectiveness of the stock market is still restricted.

As shown in Figure 4, from the analysis of the changes in the sequence approximate entropy and sample entropy from 2014 to 2020, the entropy values in 2017 when the adjustment of the control rights configuration is initiated have reached the local maximum, indicating that the adjustment of the control rights configuration has an impact on development and improvement. The operating mechanism of the stock market plays a great role in promoting. The changes in stock prices more randomly reflect the changes in the market supply and demand, and the effectiveness of the stock market has been improved. In 2020, the government will continue to introduce measures to stabilize the market and stabilize growth. Many good news to enhance market confidence have strengthened the confidence of investment participants, and finally, the value of the sequence sample entropy in 2020 has rebounded slightly.

4.2. Correlation between the Rate of Return and the Effectiveness and Complexity of the Allocation of Control Rights of Listed Companies. In order to examine the relationship between the adjustment of the allocation of control rights and the return rate, complexity, and effectiveness of the stock market, the sliding removal technique and the approximate entropy are combined with the sample entropy. The sliding window and sliding step size are both 21 data, and the sliding window is unchanged, and the approximate entropy and sample entropy of the sequence after removing 21 data in each sliding are calculated to analyze the correlation between the rate of return, complexity, and effectiveness.

As shown in Figure 5, there is a significant reverse relationship between the SSE and SZSE return rate sequences and their complexity (approximate entropy and sample entropy), that is, the complexity of the stock market becomes smaller as the return rate increases mainly because, with the initiation and implementation of the adjustment of the allocation of control rights, the institutional obstacles that are not conducive to the normal pricing mechanism of the stock market and the optimization of the function of resource allocation have been greatly improved, and the problem of the "nontradable" stocks of listed companies unable to be listed and circulated has been solved which makes the relationship between stock transactions and stock price fluctuations more in line with the operating laws of the market, reflecting that the randomness of stock price fluctuations has also increased and the predictability has been weakened. The fluctuations are getting closer and closer to random walks; thus, investors expect that the rate of return will also decrease.

As shown in Table 4, the efficiency of the stock market in developed market economies that are free and open is relatively high. The formation of stock prices is basically determined by the supply and demand relationship in the market. The formation process of stock prices shows greater randomness and regularity. Compliance is almost nonexistent; on the contrary, countries with higher market intervention or control have lower stock market effectiveness and greater regularity in stock price changes, and the formation of stock prices has certain regularity, indicating that the stock market is affected by various influences of nonmarket factors. With the initiation of the adjustment of the allocation of control rights, policy interventions and controls have gradually decreased, and the degree of openness of the stock market has gradually increased. Stock pricing mechanisms tend to improve. The effectiveness of the stock market should be fully reflected in changes in stock prices. The approximate entropy and sample entropy of the sequence should theoretically show a relatively larger value, its dynamic structure characteristics have become more complex, and the stock market system has shown changes in complexity.

As shown in Table 5, the centralized equity structure often manifests as the company's controlling shareholder's monopoly on board members, and directors' supervision of management is often trapped in their own situation. Therefore, the board of directors' supervision mechanism under this equity structure is more weak. The decentralized shareholding structure often shows that the membership of the board of directors is more complicated. This type of shareholding structure also leads to a weaker board of directors' supervision mechanism, and the directors lack the motivation to monitor the management. A moderate shareholding structure is often manifested; in that, board members are sent by several major shareholders, forming a balance of mutual checks and balances. Under this type of shareholding structure, board members will maintain their respective positions through more supervision of the management. The interests of shareholders represented may result in a win-win situation for several major shareholders.

As shown in Figure 6, the centralized equity structure is not conducive to the governance role of the company's takeover market because the centralized equity structure causes stock selling in the circulating stock market and does not pose a threat to the company's takeover. The decentralized shareholding structure makes companies easy to be acquired. In countries such as the United Kingdom and the United States, where shareholding is dispersed, active corporate takeover markets have greatly promoted and improved corporate governance. The appropriate ownership structure is more difficult for external receivers to successfully acquire because large shareholders within the company can easily unite to prevent acquisitions. According to the current "one share, one vote" system, the centralized shareholding structure often leads to a mere formality in the convening of general meetings. The controlling shareholders completely manipulate the voting results, and the majority of small and medium shareholders generally give up the exercise of shareholder power. The decentralized shareholding structure makes most shareholders have no enthusiasm to exercise shareholder rights, which will cause serious insider control problems, and most shareholders will be easily manipulated by management. In 


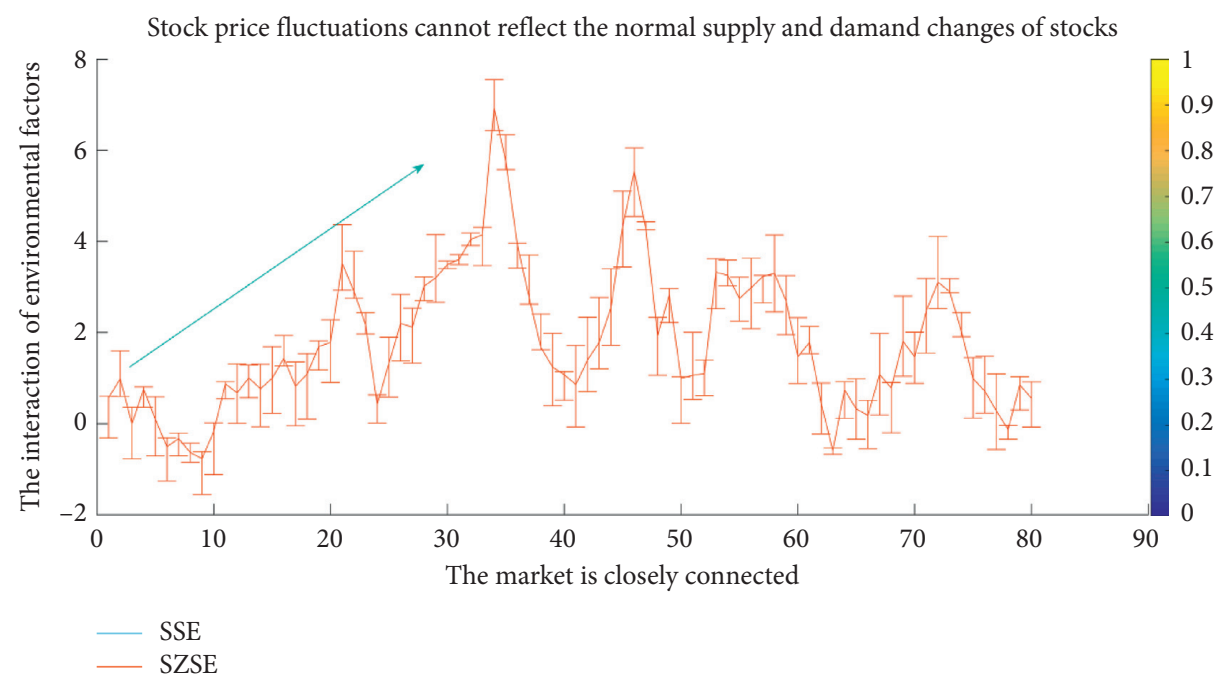

FIgURE 4: Stock price fluctuations cannot reflect the normal supply and demand changes of stocks.

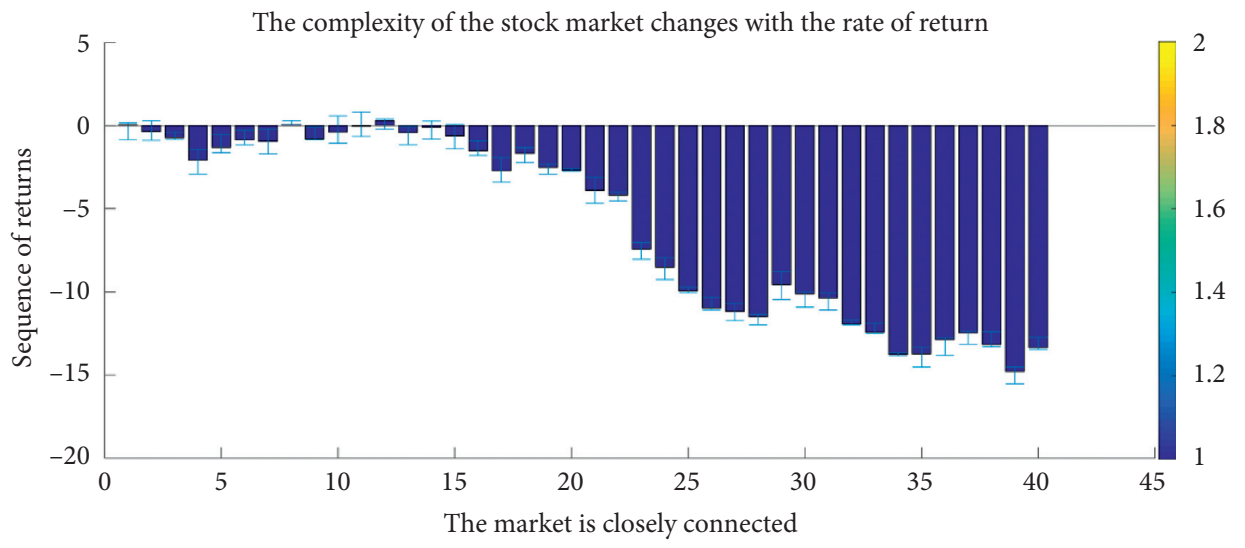

SSE, SZSE

Figure 5: The complexity of the stock market changes with the rate of return.

TABLE 4: The randomness of stock price formation.

\begin{tabular}{|c|c|c|c|c|c|c|}
\hline Item & Cost & Corporate & Performance & Sequence & Approximate & $S$-entropy \\
\hline SSE & 3.11 & 2.98 & 1.4 & 1.34 & 1.43 & 3.31 \\
\hline SZSE & 5.19 & 3.49 & 3.68 & 2.76 & 4.28 & 2.67 \\
\hline Approximate & 4.95 & 5.97 & 2.49 & 1.31 & 1.44 & 4.88 \\
\hline Sample & 4.81 & 2.82 & 2.65 & 1.8 & 2.39 & 1 \\
\hline Effectiveness & 6.21 & 1.68 & 3.91 & 5.79 & 3.55 & 5.07 \\
\hline Predict & 4.09 & 2.48 & 6.47 & 3.98 & 4.35 & 6.73 \\
\hline
\end{tabular}

TABLE 5: Performance of the concentrated ownership structure.

\begin{tabular}{|c|c|c|c|c|c|c|}
\hline Item & Theory & Effectiveness & Structure optimization & Equity concentration & Shareholder power & Monitoring mechanism \\
\hline Management & 0.1 & 0.51 & 1.57 & 0.51 & 0.08 & 1.85 \\
\hline Allocation & 1.6 & 2.76 & 1.81 & 2.84 & 3.38 & 2.95 \\
\hline Equity & 5.56 & 2.75 & 5.89 & 2.73 & 3.77 & 5.59 \\
\hline Configuration & 2.41 & 5.46 & 2.28 & 3.07 & 5.89 & 4.36 \\
\hline Scientific & 4.6 & 3.06 & 3.21 & 2.77 & 4.37 & 4.92 \\
\hline Guiding & 1.2 & 1.94 & 2.92 & 5.84 & 2.88 & 2.41 \\
\hline
\end{tabular}




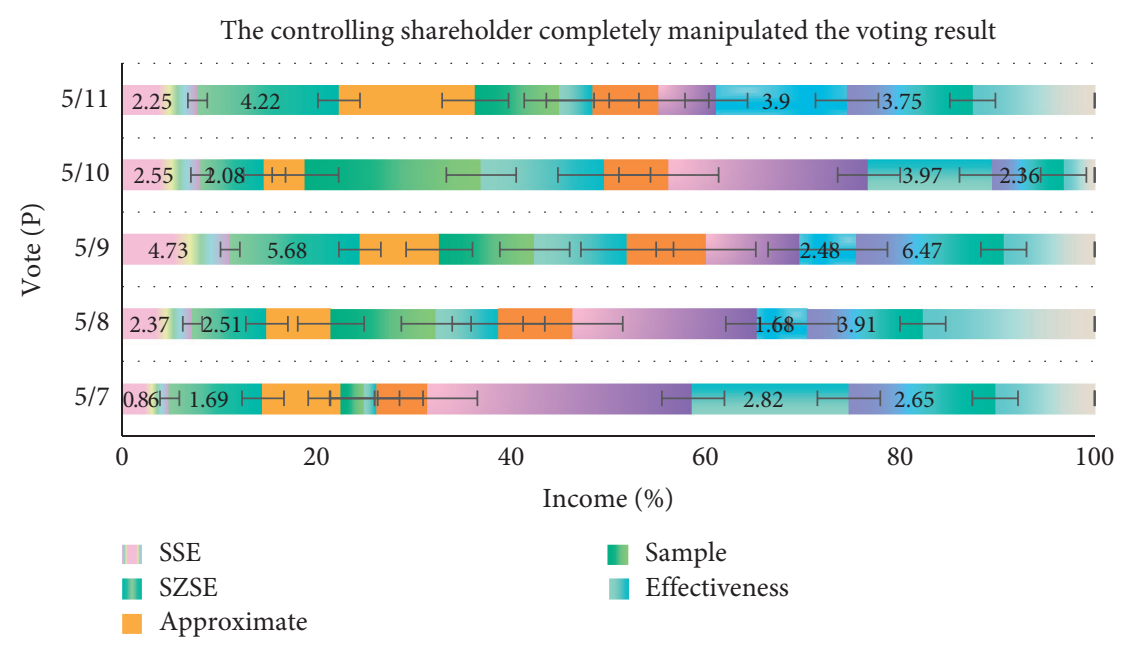

FIGURE 6: The controlling shareholder completely manipulated the voting result.

a moderate shareholding structure, several large shareholders generally send their representatives to participate in the general meeting of shareholders and exercise voting rights. Relatively speaking, under this ownership structure, the exercise of shareholder rights represents the interests of more shareholders.

As shown in Figure 7, in the absence of the guidance of the optimal allocation model of equity, the general law of equity allocation in the management buyout of listed companies in our country further verifies whether the previous empirical conclusions are valid and scientific. This represents a preacquisition note by observation. It turns out that this is during a proper increase in stock concentration acquisitions. The result of the actual investigation is that, after the implementation of the management buyout, there was a high degree of equity concentration. There were no changes in the equity concentration of two companies, and only three companies had their equity concentration decreased.

According to the results of the previous empirical research, it can be seen that increasing the degree of equity checks and balances does not necessarily promote the improvement of company performance; only when the degree of equity checks and balances is lower than the increase, this should reduce the degree of equity checks and balances of these listed companies; otherwise, it may not be conducive to the improvement of company performance. As shown in Table 6, if the degree of equity checks and balances of these listed companies is increased, it may cause a decrease in company performance. In order to further verify this inference, we once again investigated the return on total assets. The code is referred to as the return on total assets. Note that the performance of each company has been significantly reduced. Therefore, we believe that the increase in equity checks and balances may be one of the main reasons for this result.
As shown in Figure 8, many control rights allocation models are based on agency costs. Most of these models assume that an enterprise's income is asymmetry in information among insiders. The former can occupy all the income that is not paid to the latter. Under this assumption, it is concluded that due to the limitation of the managers' own funds and the protection of their own interests by external investors, this has led to more use of liabilities in management buyouts. Secondly, the managers adopt more dual securities, which are both equity and debt. In terms of rights, there are residual claims and fixed claims. In many debt contracts signed with managers, some investors often attach some conditions for converting debts into equity, which not only guarantees the minimum rate of return for investors but also enables investors to obtain high returns. Through the above investigation of the equity allocation of management buyouts of listed companies in our country, the effectiveness of the previous empirical conclusions is basically verified. Therefore, the equity optimization allocation model designed in this article has certain scientific and guiding significance for the equity allocation in our country's management buyouts.

As shown in Figure 9, the model established in this article is universal, and it is this universality that makes it not entirely suitable for all types of companies. In the empirical study, through the curve relationship between cost and corporate performance and the general model of the learning model and the allocation of stock optimization, this provides useful guidance for the management to optimize the allocation of the company's equity structure after the acquisition. In fact, it is unrealistic to expect to establish an optimal model of the equity structure suitable for all types of enterprises. The significance of the model established in this article is to provide a way to find an optimal allocation model of equity, that is, the concentration of equity and the balance of equity. Combine land and use curve estimation method to establish an optimal allocation 


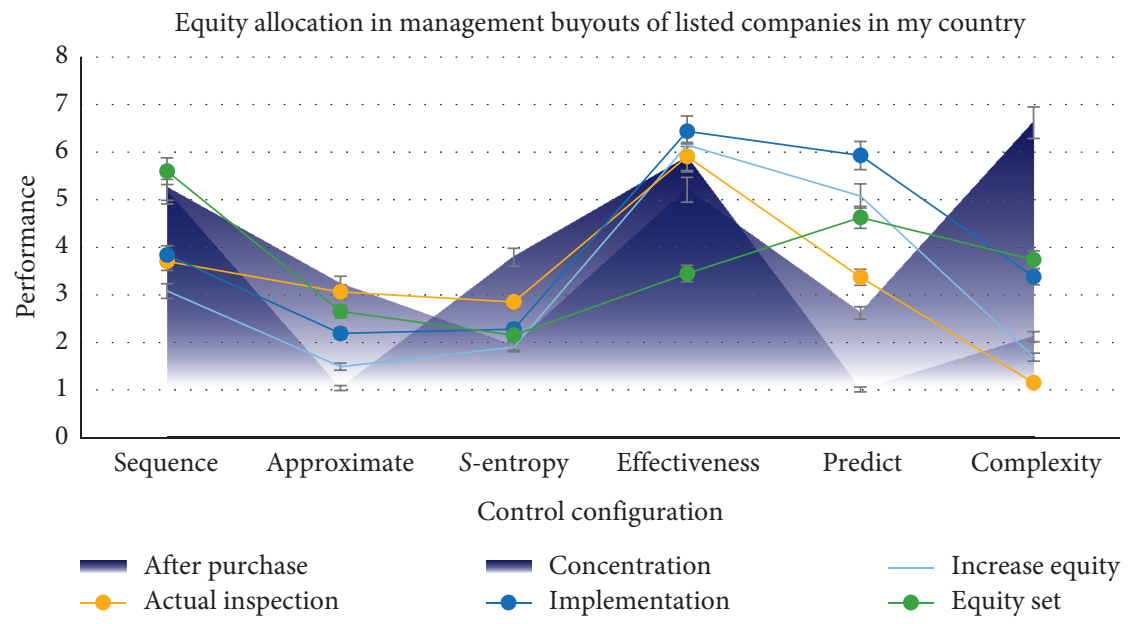

FIGURE 7: Equity allocation in management buyouts of listed companies in our country.

TABle 6: Promote the improvement of company performance.

\begin{tabular}{lcccccc}
\hline Item & After purchase & Increase equity & Concentration & Actual inspection & Implementation & Equity set \\
\hline Sequence & 5.17 & 3.08 & 5.25 & 3.7 & 3.84 & 2.6 \\
Approximate & 1.04 & 1.49 & 3.23 & 3.06 & 2.85 & 2.65 \\
S-entropy & 3.79 & 1.9 & 1.93 & 5.91 & 2.15 \\
Effectiveness & 5.88 & 6.15 & 5.21 & 3.37 & 6.44 \\
Predict & 1.01 & 5.08 & 2.62 & 1.15 & 5.93 \\
Complexity & 2.12 & 1.69 & 6.62 & & 3.45 \\
\hline
\end{tabular}

Listed company management buyout equity allocation

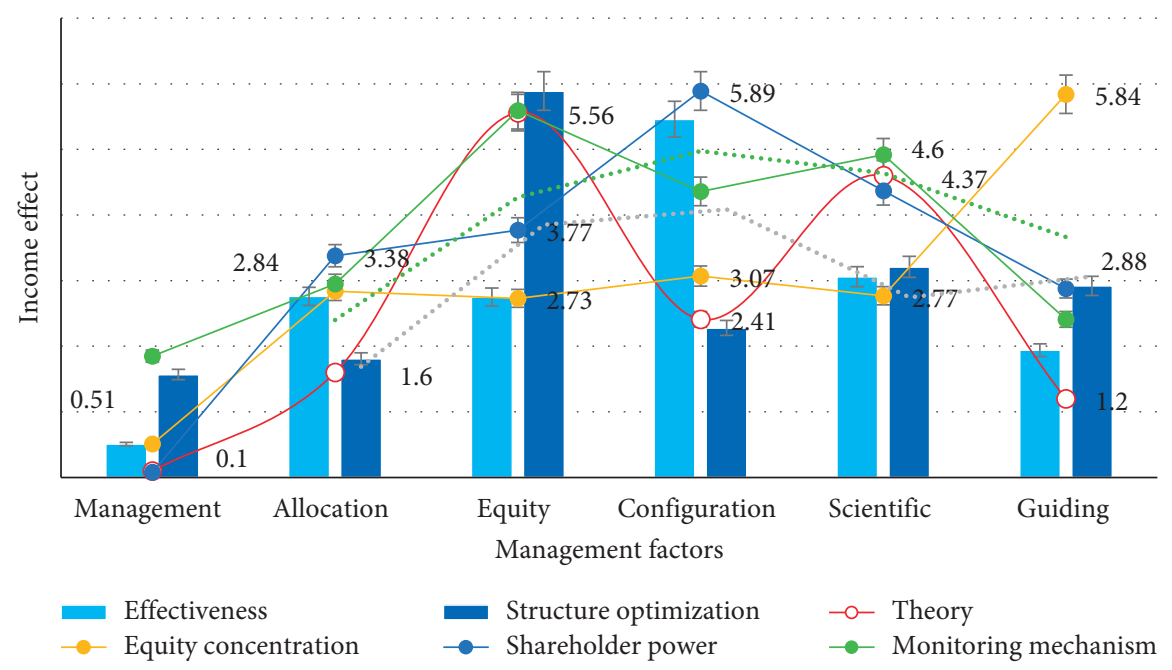

Figure 8: Listed company management buyout equity allocation. 


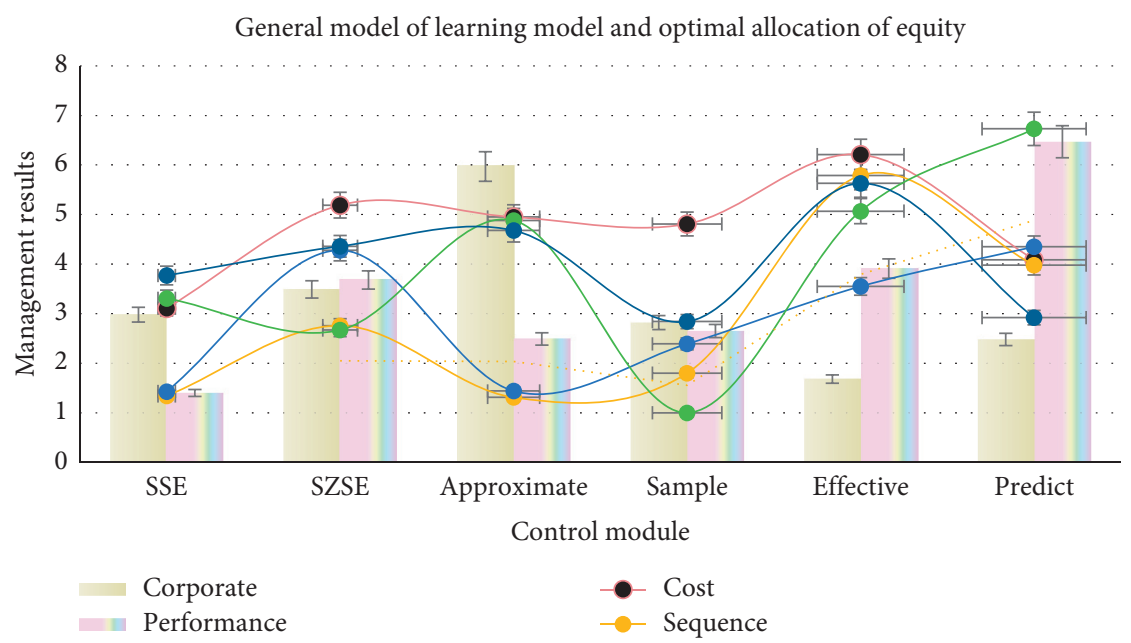

Figure 9: General model of learning model and optimal allocation of equity.

model of the equity structure. At the end of this part, case analysis is used to test the designed equity optimization allocation model, and the results show that the model is scientific and effective.

\section{Conclusions}

This paper uses the theory of complexity entropy to measure and analyze the approximate entropy and sample entropy of stock market returns from the perspective of the adjustment of control rights allocation and system thinking. The main conclusions are as follows. (1) According to the definition of randomness, the hypothesis of market efficiency, and the theory of approximate entropy and sample entropy, it is proved that the value and randomness state of the approximate entropy and sample entropy of the stock market can reflect the logical relationship between the complexity and effectiveness of the stock market and prove the randomness and effectiveness of the stock market. (2) By measuring the dynamic values of the approximate entropy and sample entropy of the stock market return sequence during the year and the control allocation adjustment stage and analyzing the change characteristics of the sequence complexity, it shows that the randomness of the stock market after the control allocation adjustment has been enhanced. Effectiveness has been improved, and it presents greater complexity. (3) The complexity of the stock market sequence from before the adjustment of control rights allocation to after the adjustment of control rights allocation shows an overall increasing trend. The sample entropy is more accurate than the approximate entropy in the sensitivity of the detection data.

From the perspective of the dynamic changes in the complexity of the stock market before and after the adjustment of control rights allocation and the relationship between its return rate and its complexity, although the effectiveness of the stock market after the adjustment of control rights allocation has improved to a certain extent, the increase is small. Therefore, the allocation of control of the company needs to be further improved, and the ability to allocate resources needs to be optimized. The author believes that, under the premise of ensuring the normal and stable operation of the stock market, we should continue to implement market reforms, establish a sound regulatory system, improve the speed and efficiency of effective information dissemination and ultimately achieve further enhancement of the effectiveness of the stock market, and form a reasonable and complete listing. The formation mechanism of corporate control rights maximizes the efficiency of resource allocation optimization in the capital market and promotes the healthy development of the stock market in accordance with its own laws.

Although this article has done a lot of work on research, there are still some deficiencies in the article due to my level and time constraints. For example, in the economic interpretation of the management control allocation index, a deep economic foundation is required, and this article does not do enough in this respect. Another example is when investigating the case of management control allocation plan, only the information of the management control allocation index of listed companies is public, which leads to a small number of case samples, and this article only selects the sample company control allocation index before comparing the performance indicators of one year with that of the control right allocation index, the rationality of which is questionable. Future research in this field should pay more attention to corporate governance issues. You can use the China Corporate Governance Evaluation Index to investigate whether the company after the implementation of the control allocation plan is developing in a positive way in corporate governance and whether it is a successful experience or failed. The lessons will help the subsequent enterprises to formulate management control allocation plans.

\section{Data Availability}

The data that support the findings of this study are available from the corresponding author upon reasonable request. 


\section{Conflicts of Interest}

There are no potential competing interests in our paper.

\section{Acknowledgments}

There is no funding was received for this article.

\section{References}

[1] M. Zhou, "On the disclosure of internal control information of listed companies," Enterprise Technology Development, Academic Edition, vol. 37, no. 2, , pp. 114-116, Cambridge, MA, USA, 2018.

[2] Q. Qu, K.-Y. Chen, Y.-M. Wei, Y. Liu, S.-B. Tsai, and W. Dong, "Using hybrid model to evaluate performance of innovation and technology professionals in marine logistics industry," Mathematical Problems in Engineering, vol. 2015, Article ID 361275, 8 pages, 2015.

[3] H. Ying, "Research on the measurement and influencing factors of commercial bank's capital mismatch-take listed banks for example," International Core Journal of Engineering, vol. 5, no. 9, pp. 221-226, 2019.

[4] T. Pan, "Research on the influence of macroeconomic policy uncertainty on cash dividend level of enterprises-based on the empirical analysis of listed companies in China's main board and small and medium-sized board," World Scientific Research Journal, vol. 6, no. 5, pp. 95-111, 2020.

[5] Xiaofang and Y. Zhao, "Research on the impact of government subsidies on the development capabilities of listed companies-based on the perspective of equity concentration of renewable energy companies," Journal of Inner Mongolia University of Finance and Economics (Comprehensive Edition), vol. 17, no. 4, pp. 25-28, 2019.

[6] Q. Zhang and P. Erasmus, "Study on the relationship between ownership structure and corporate performance: evidence from Chinese companies listed on the GEM board," International Business \& Economics Research Journal (IBER), vol. 15, no. 2, pp. 27-39, 2016.

[7] E. J. Lusk, M. Halperin, and B. D. Zhang, "The balanced scorecard: suggestions for rebalancing," Problems and Perspectives in Management, vol. 4, no. 2, pp. 100-114, 2017.

[8] P. P. Gupta, H. Sami, and H. Zhou, "Do companies with effective internal controls over financial reporting benefit from sarbanes-oxley sections 302 and 404?" Journal of Accounting, Auditing \& Finance, vol. 33, no. 2, pp. 200-227, 2018.

[9] U. Mishra, J. Tijerina-Aguilera, S. Tiwari, and E. C.-B. Leopoldo, "Retailer's joint ordering, pricing, and preservation technology investment policies for a deteriorating item under permissible delay in payments," Mathematical Problems in Engineering, vol. 2018, Article ID 6962417, 14 pages, 2018.

[10] L. Dalla Valle, M. E. De Giuli, C. Tarantola, and C. Manelli, "Default probability estimation via pair copula constructions," European Journal of Operational Research, vol. 249, no. 1, pp. 298-311, 2016.

[11] C. Ding, Z. Zhao, X. Zhu et al., "Application of neural network in intelligent fire alarm system," Sensors and Microsystems, vol. 37, no. 1, pp. 154-156, 2018.

[12] W. Shouqing, W. U. Di, P. Wei et al., "Allocation of control rights between governments and companies in urban development PPP projects," Journal of Tsinghua University (Science and Technology), vol. 57, no. 4, pp. 369-375, 2017.
[13] P. Boeing, "The allocation and effectiveness of China's R\&D subsidies-evidence from listed firms," Research Policy, vol. 45, no. 9, pp. 1774-1789, 2016.

[14] L. Yang-Bok, "A study on introducing dual class stock into the Korean commercial code," Business Law Review, vol. 31, no. 2, pp. 91-118, 2017.

[15] L. Hu and N. Li, "Research on the construction of machine learning platform under big data technology," Computer Knowledge and Technology, vol. 15, no. 10, pp. 157-159, 2019.

[16] A. J.-P. Tixier, M. R. Hallowell, B. Rajagopalan, and D. Bowman, "Application of machine learning to construction injury prediction," Automation in Construction, vol. 69, no. 8, pp. 102-114, 2016.

[17] O. Weisman, M. Chetouani, C. Saint-Georges et al., "Dynamics of non-verbal vocalizations and hormones during father-infant interaction," IEEE Transactions on Affective Computing, vol. 7, no. 4, pp. 337-345, 2017.

[18] M. Kawamura, T. Suzuki, and K. Kobayashi, "Construction of a dividual model using a reinforcement learning based Bayesian network," IEEJ Transactions on Electronics, Information and Systems, vol. 137, no. 2, pp. 288-293, 2017.

[19] J. Kim and S. Park, "Field applicability of a machine learningbased tensile force estimation for pre-stressed concrete bridges using an embedded elasto-magnetic sensor," Structural Health Monitoring, vol. 19, no. 1, pp. 281-292, 2020.

[20] Y. Zhou, S. Zheng, and G. Zhang, "Machine learning-based optimal design of a phase change material integrated renewable system with on-site PV, radiative cooling and hybrid ventilations-study of modelling and application in five climatic regions," Energy, vol. 192, no. 1, pp. 1-21, 2020.

[21] G. Liu, J. H. Nzige, and K. Li, "Trending topics and themes in offsite construction(OSC) research," Construction Innovation, vol. 19, no. 3, pp. 343-366, 2019.

[22] K. Tangirala, N. Herndon, and D. Caragea, "A comparative analysis between $k$-mers and community detection-based features for the task of protein classification," IEEE Transactions on NanoBioscience, vol. 15, no. 2, pp. 84-92, 2016.

[23] H. Sun, "Research on the construction of electronic resources of university library based on text similarity," Intelligent Computers and Applications, vol. 8, no. 5, pp. 155-158, 2018.

[24] X. Ma, X. Yuan, and Y. Sun, "Application of wavelet neural network in the mine deformation monitoring," Mine Measurement, vol. 44, no. 6, pp. 44-47, 2016.

[25] B. Liu, L. Jin, and Y. Liu, "Study on application problems of DRGs performance evaluation indicators in the evaluation in the specific hospital," Chinese Health Industry, vol. 15, no. 10, pp. 29-31, 2018.

[26] K. Henchi, M. Fafard, M. Talbot et al., "Application of artificial neural networks to the identification and detection of the damage in bridges," Revue Européenne des Éléments Finis, vol. 7, no. 3, pp. 257-272, 2016.

[27] L. X. Weiyang, "The application of deep convolution neural network to building extraction in remote sensing images," World Scientific Research Journal, vol. 6, no. 3, pp. 136-144, 2020. 